\title{
Informetrics needs a foundation in the theory of science
}

\author{
Hjørland, Birger
}

Published in:

Theories of Informetrics and Scholarly Communication

Publication date:

2016

Document version

Publisher's PDF, also known as Version of record

Citation for published version (APA):

Hjørland, B. (2016). Informetrics needs a foundation in the theory of science. In C. R. Sugimoto (Ed.), Theories of Informetrics and Scholarly Communication (pp. 20-46). De Gruyter.

http://www.degruyter.com/view/product/379257?rskey=jBT3n9\&onlyResultQuery=Theories\%20of\%20Informetric s\%20and\%20Scholarly\%20Communication 
Birger Hjørland

\section{Informetrics Needs a Foundation in the Theory of Science}

\section{Introduction}

The terms "bibliometrics", "informetrics" and "scientometrics" are-unless otherwise specified-considered synonymous in this chapter. They refer to quantitative studies of documents, collections of documents, and derived patterns (e.g., maps based on co-citations or bibliographic coupling, or evaluative techniques such as journal impact factor (JIF), or the h-index). They also cover webometrics and statistical patterns such as Bradford's law, Lotka's law, and Zipf's law.

Traditionally, many informetrics studies have been made by using scientific and scholarly databases (e.g., Science Citation Index) and those studies thereby represent studies of scholarly literatures (thus this subset of informetrics may be termed "scientometrics"). By implication, scientometrics is a "science of science", a "metascience" or a field of "science studies" as also put forward by Bates (1999, p. 1044). The family of metasciences includes fields such as the history of science, the philosophy of science, and the sociology of science, mentioning only the most important, ${ }^{1}$ where the term "science" is not limited to natural science but covers all fields of scholarship. The main points in this paper are: (1) information science with informetrics belongs to the meta-sciences, (2) these meta-sciences are mutually interdependent, (3) all meta-fields are also dependent on subject knowledge, and (4) "post-Kuhnian" views of knowledge are based on social, historical, and pragmatic perspectives (rather than on individualistic and foundational perspectives).

We shall start by having a brief introduction to the most important metasciences: The history of science typically studies lines of development (diachronic analysis) in science and the life and works of great scientists often based on scientific literature as well as unpublished sources focusing on science as a whole, a single discipline, or a specific period or aspect. The principles of such historical studies are developed in the field called historiography and the principles of the history of science are developed in the subfield called historiography of science.

1 Here, I am using science studies in a broader meaning than, for example, Collin (2011) who does not consider philosophy of science as a part of science studies. 
The philosophy of science is typically based on rationalist principles putting forward normative criteria for scientific work and scientific methodology and is not usually based on empirical or historical studies. ${ }^{2}$ The logical positivists suggested one family of norms in the first part of the $20^{\text {th }}$ century: there is a universal and a priori scientific method; theories must be translatable into observational terms; the doctrines of behaviorism, operationalism, and methodological individualism; and the reduction of research objects into "variables". Such norms can still be found in textbooks of empirical methodologies in the social sciences, although logical positivism today is generally considered an unsuccessful project based on unfruitful premises. Philosopher Karl Popper developed another set of norms based on the principle of falsificationism whereby good research should: (1) provide scientific statements, hypotheses, and theories which are precise in having an inherent possibility to be proven false, (2) should not be based on empirical generalisations, but should put forward theories which are bold and courageous, and (3) should submit scientific theories to rigorous tests. The implications of theories should be logically deduced and empirically tested; the best scientific knowledge is able to resist careful scrutiny from the scientific community. Philosophical positions and traditions such as hermeneutics, pragmatism, critical studies, and qualitative methodologies developed another set of norms which tend to emphasise the historical nature of thinking; the active role of the researcher; the study of conceptions, theories, and the dialectics between subject and object; and emphasize that an object is always an object for a subject and a subject is always historically, socially, and culturally situated.

The sociology of science typically studies empirical studies on scientific activities, both internally in science and in their relations to broader society (power, economy, and policies). The field of scientometrics is often considered by sociologists of science as a part of their field (just as we in information science consider it part of our field). The field is closely related to "cultural studies of science". Among the important concepts in the sociology of science are "Mode 2" research and "triple helix" which emphasise the growing influence of industrial and commercial interests in the scientific system. Other important questions involve gender issues, the role of social class and ethnicity, the career system, and issues that motivate scientists to do things in the way they are done (versus how they could have be done).

Information science with informetrics typically studies information systems and information services; "memory institutions" such as research libraries, bib-

2 Although Kuhn's philosophy of science, for example, represents a historicist philosophy of science. 
liographic databases, knowledge organisation systems (see Stock, this volume); as well as the users, non-users, and potential users of such information systems and services. This field studies the whole system of actors, institutions, and services connecting information producers and users (cf., Søndergaard, Andersen, \& Hjørland, 2003). Information science is largely an empirical field, but is also a normative field (studying, promoting, and providing standards for many aspects of scientific communication). While relatively distinct from the other meta-sciences given its purpose to contribute to optimal scientific communication and utilisation of recorded knowledge, information science often represents a design or construction perspective and a relation to the practice of librarianship, documentation, and information services that makes it relatively unique.

When it is claimed that informetrics belongs to the meta-sciences, it may be argued that this field is much broader than the scientific domain and today includes, among other things, webometrics and thus link-structures from all sectors of broader society as well as ordinary peoples' relation to information. Although this is correct, two things should be recognized: (1) Within the narrower field of science, it is important to consider the relation between scientometrics and the domain of science in order to understand and explain bibliometric patterns; and (2) In the broader field of other sectors of society and of everyday information use, the same principles may also provide a fruitful basis for understanding information science and informetrics. It is wrong and harmful to ignore the field of meta-sciences because it is considered too narrow (which is an argument frequently encountered in schools of library and information science because of the emphasis often placed on public libraries and information services for broader society). We shall return to the importance of the philosophy of science for nonscientific domains later.

Meta-sciences are mutually interdependent and all of them are also-first and foremost-dependent on subject knowledge of the fields of knowledge they are studying. In order to understand and evaluate research on say, the history of psychology, one must do so based on knowledge about the field of psychology, what counts as psychological knowledge, and what is a success or a blind alley in psychology. The same is the case when we have to interpret or evaluate a bibliometric map of psychology -and in order to even draw it, first we need to identify which documents are psychological on which to draw the map (this is discussed in details later in this chapter). In both cases, we have an example of a hermeneutic circle: in order to study a domain, you must delimit it, and in order to delimit it, you must have knowledge about it. In other words: A lack of subject knowledge on the part of meta-scientists may provide problematic interpretations of the empirical patterns observed. 
Examples of interaction between the meta-sciences are Garfield's (2004) bibliometric contribution to historiography and Griffith's (1979) bibliometrically based criticism of some assumptions in the philosophy of science. On the other hand, Kuhn's (1962) theory of paradigms inspired bibliometric researchers to try to identify paradigms empirically (cf. Chen, 2003). This chapter will briefly introduce the relation between philosophy of science and other meta-sciences, but will mainly focus on the relation between the theory of science and informetrics.

\section{Philosophy of science after logical positivism}

Often stated, Thomas Kuhn's (1962) book the Structure of Scientific Revolutions brought an end to logical positivism. Although this is disputed, ${ }^{3}$ the opposition between "positivism" and "post-Kuhnian philosophy" provides the foundation for this chapter; but what is (logical) positivism and what-if anything-has really changed in the ground swell of Kuhn?

Defining "positivism" is not easy. ${ }^{4}$ There are many different positions in both classical and logical positivism, just as there are different interpretations of these positions (see, for example, Reisch, 2005 for a recent re-interpretation). A common view is that the term "positivism" includes three main characteristics:

1. the use of quantitative methodologies,

2. the use of scientific methods (as opposed to hermeneutic methods in the social sciences and humanities), and

3. the belief in realism and objectivity.

Given that Kuhn opposed positivism, an easy conclusion is that the understanding of positivism expressed in the first and second points must be wrong. Kuhn was a physicist by training and physics is based on measurements-hence a quantitative discipline. Of course, Kuhn did not end physics or its quantitative methodology and therefore it does not make sense to understand positivism in the first and second sense. Kuhn's revolution in the philosophy of science must have another

3 The Danish philosopher Stig Andur Pedersen (1995) demonstrated that even if Kuhn's theory represents a clash with positivist ideas it is in many ways a natural continuation of the work of the logical positivists in the 1940s and 1950s . Friedman (2003), Moges (2010) and Reisch (1991) made related observations. Tsou (2015), however, maintains that the logical positivism of Rudolf Carnap and Kuhn's work represent two distinctive traditions of doing philosophy of science.

4 “Questions such as 'Is thesis T a positivist (empiricist, idealist, realist etc.) thesis?' are notoriously difficult.” (Bird, 2004, p. 338). 
meaning (if the first view was correct, informetrics per definition would be positivist, which I will argue it cannot be).

The third view (that positivism is a realist position) is more complicated, but is generally considered wrong in the philosophy of science. For logical positivism, speaking about any reality behind observations or causing observations is metaphysical and metaphysics is considered illegitimate. "What exists in reality" is considered a metaphysical question and opposed to the positivist spirit. It is rather well-established in the philosophy of science that empiricism/positivism and realism are different positions. It can even be argued that positivism is less realistic compared to more interpretative positions because it is better to have explicit subjectivity than to have subjectivity disguised as objectivity. Such an argument will be put forward below.

What then is positivism? Perhaps we can best describe it as the belief in "the Leibnizian ideal”:

The Leibnizian ideal holds that all disputes about matters of fact can be impartially resolved by invoking appropriate rules of evidence. At least since Bacon, most philosophers have believed there to be an algorithm or set of algorithms which would permit any impartial observer to judge the degree to which a certain body of data rendered different explanations of those data true or false, probable or improbable [...] But whether optimists or pessimists, rationalists or empiricist, most logicians and philosophers of science from the 1930s through the 1950 s believed, at least in principle, in the Leibnizian ideal.

(Laudan, 1984, p. 5-6)

Although Kuhn was not the first to question this ideal, ${ }^{5}$ The Structure of Scientific Revolutions nonetheless had the greatest impact on the fall of the Leibnizian ideal. What Kuhn brought to the forefront in the philosophy of science was the understanding that scientists are trained and socialized in paradigm-centered scientific communities and much of what they do and think is based on the experiences from their daily work with experiments. According to Mallery, Hurwitz, and Duffy (1992), the notion of a paradigm-centered scientific community is analogous to Gadamer's notion of a linguistically encoded social tradition. Therefore, we could say that Kuhn's philosophy is closer to hermeneutics than to positivism. Kuhn thus contributed in changing philosophy of science from an individualist to a social epistemology (cf. Wray, 2011). Not only do explicit theories govern scientists' activities, but also do tacit knowledge.

5 Names like Dewey (1929), Feyerabend (1975), Hanson (1958) and Toulmin (1953) deserve to be mentioned in this context. 
Logical positivism must therefore be understood in contrast to socially and historically oriented philosophies of science. Logical positivism was an attempt to combine two former traditions-rationalism and empiricism:

\begin{abstract}
logical positivism arose as the joint product of two intellectual traditions [rationalism and empiricism] that conflicted deeply with one another: In attempting to unite these traditions, its adherents created an extremely influential approach to philosophy but one that embodied serious intellectual tensions from its dual ancestry.
\end{abstract}

(Smith, 1986, p. 64)

In order to understand philosophy of science after logical positivism, it is therefore important to understand the inherent limitations of empiricism and rationalism (in this paper only empiricism is analyzed).

As a doctrine in epistemology, empiricism holds that all knowledge ultimately is based on experience; but empiricism should not be confused with the need for science to be empirical, is it rather about certain ideals governing empirical studies. Widely recognised today, sciences are empirical in a broad understanding of the term. In psychology, empiricism is in particular associated with behaviorism, the "objective" study of stimuli and responses in organisms. The limitations of behaviorism were strongly exposed by the linguist and cognitive scientist Noam Chomsky (who explicitly subscribed to rationalism), who wrote:

A typical example of 'stimulus control' for [the behaviorist] Skinner would be the response to a piece of music with the utterance Mozart or to a painting with the response Dutch. These responses are asserted to be 'under the control of extremely subtle properties' of the physical object or event (108). Suppose instead of saying Dutch we had said Clashes with the wallpaper, I thought you liked abstract work, Never saw it before, Tilted, Hanging too low, Beautiful, Hideous, Remember our camping trip last summer?, or whatever else might come into our minds when looking at a picture (in Skinnerian translation, whatever other responses exist in sufficient strength). Skinner could only say that each of these responses is under the control of some other stimulus property of the physical object.

(Chomsky, 1959, p. 31)

The behaviorism of Skinner is a version of logical positivism attempting to predict and control human behavior in terms of "stimuli" and "responses". It may understand itself as "objective science" but, as Chomsky's criticism demonstrates, in the case where a human being is looking at a painting and provides some response, we are unable to tell what in the painting elicited the specific response: the stimulus is not objectively given for the researcher. Because there is no objective way to identify the stimulus, there is of course a great possibility that the behaviorist/ positivist psychologist uses his/her own subjective perception of the picture as the basis for studying other peoples' stimulus-response relations. If the psychologist 
is unaware of how the picture may be understood by different cultures and subcultures, his/her own cultural understanding may influence his/her perception of the psychology of the observer.

An example from history may also illustrate the same point. When history was established as a scholarly discipline in the United States, "universalism” was assumed, i.e., that,

Truth was one, the same for all people. It was, in principle, accessible to all and addressed to all. Particular commitments - national, regional, ethnic, religious, ideological-were seen as enemies of objective truth [...] The close connection which historians saw between detachment and objectivity made them sympathetic to Mannheim's celebration of the vantage point of free-floating and socially detached observers, whose liberation from particularist loyalties allowed them to approach closer to objectivity.

(Novick, 1988, p. 469)

However, this universalism was later challenged:

The entry of large numbers of Jews into the upper reaches of the [historical] profession in the 1950s and early 1960s was widely seen as the fulfillment of universalist norms. It was otherwise with the arrival of blacks and women from the late sixties and onward. For their rise to prominence within the profession coincided with a new, assertive, particularist consciousness which both directly and indirectly challenged universalist norms. They defined themselves not as "historians who happened to be Negroes," with a consensually acceptable integrationist standpoint, but as black historians, committed to one or another form of cultural nationalism ...

(Novick, 1988, p. 470; emphasis in original)

In short: Positivism is associated with the idea that researchers' subjectivity does not matter or may be eliminated while post-Kuhnian philosophy acknowledges the influence of subjectivity. The idea that male, middle-class, white historians may be able to describe history in neutral ways has been challenged just as has the idea about behavioral psychologists being able to describe stimulus-response patterns objectively. Somewhat paradoxically this makes positivism a less objective and less realist science compared to hermeneutics and related traditions: positivism turns out to be a form of subjective idealism in which the researcher's cultural background and theoretical understanding is neglected and therefore cannot be taken into account. ${ }^{6}$

\footnotetext{
6 An anonymous reviewer commented: "positivism turns out to be a form of subjective idealism-only if you're characterizing positivism from an anti-positivist position, surely? There's no 'paradox' there." Answer: Yes, there is a real paradox in positivism. You cannot get rid of this criticism just by ignoring it. The implication of what the reviewer says is that any position is a
} 
Kuhn introduced the concept of "paradigms", which has been heavily discussed. In this chapter a paradigm is understood as a system of assumptions, concepts, values, and practices that constitute a way of viewing reality. Paradigms influence the way scientists see things and describe them. Perception is not a neutral collection of data on which theories are afterwards developed, but perception itself is theory-laden. Scientists in different paradigms see the world differently and describe it differently. Concepts in one paradigm are not the same in another paradigm thus making paradigms incommensurable. This is in sharp conflict with the Leibnizian ideal because it changes the nature of scientists from objective calculators to socially conditioned subjects. It also means that scientific knowledge is not seen as a commonly agreed body of knowledge, but as different theories full of disagreements (although Kuhn himself saw science as governed by one paradigm at a time, the general post-Kuhnian tendency is to understand science as consisting of competing paradigms at any point in time). Kuhn added the historicist understanding that knowledge develops in historically constituted paradigms and this historical or evolutionary dimension (in addition to the social dimension) is important in order to understand the development of science. Finally, Kuhn also added the axiological dimension: Scientists may be governed by different goals and values.

The following quote by Michael Kleineberg expresses a view that has gained a stronghold today:

\begin{abstract}
In the process of knowing, the known and the knower seem to be inextricably interwoven. Knowledge as it appears in the consciousness of human beings is always knowledge about something for someone. The now widely accepted epistemic pluralism maintains that the validity of knowledge claims depends on the epistemic framework of the knower and cannot be judged from a neutral "view from nowhere". The knower as an agent of epistemic activity is always already embodied as a material organism and embedded in a social and cultural environment at a certain point in time and space. In other words, the prerequisites to create, represent, organize, and communicate knowledge or information are limited by preconditions which are investigated by theories of knowledge and constitute the epistemological dimension.
\end{abstract}

(Kleineberg, 2014, p. 80)

This quote may sound relativistic (and Kuhn is often accused of being relativist). ${ }^{7}$ Of course, any paradigm is not as fruitful as any other, although the difficulty is

fruitful as any other and that disagreeing arguments can just be ignored. To say that any theoretical position is true from its own point of view represent a problematic relativism.

7 An anonymous reviewer of this chapter wrote: "In this very interesting chapter, the author argues that, as meta-scientists, designers and evaluators of informetric studies should heed certain claims of "post-Kuhnian" philosophy of science-e.g., that the goal of science/meta-science is 
again that an evaluation of paradigms cannot be accomplished from a neutral "view from nowhere". However, as Kleineberg (2014) writes: "If the claim 'nothing is valid for all contexts' was true, then it would contradict itself since this statement appears as a universal claim as well” (p. 85).

We conclude this section with a quote from historian Christopher Lloyd:

"Perhaps the greatest advance in understanding the nature of explanation made in the post-positivist and post-Kuhnian era is the general realization that methodologies, theories, and explanations are related to each other via extra-logical, historically variable constellations variously described as 'background knowledge', 'traditions', 'paradigms', 'research programmes', 'fields', or 'domains'. We can call all of these 'framework concepts.'

(Lloyd, 1993, p. 32)

\section{Intermezzo: social constructivism is not an alternative to positivism}

Before we consider the implications of the Kuhnian revolution in the philosophy of science, it is necessary to consider social constructivism because this position is strongly influential today:

Originally proposed by sociologists of science, constructivism or social constructivism is a view about the nature of scientific knowledge held by many philosophers of science. Constructivists maintain that scientific knowledge is made by scientists and not determined by the world. This makes constructivists antirealists. [...] Constructivism is more aptly compared with Berkeley's idealism.

(Downes, 1998, vol. 2, p. 624)

Sociologists of science, such as Bloor (1991), a main figure in the so-called "Strong Programme", conduct empirical studies of (natural) scientists and some of them claim from such findings to demonstrate how scientists construct scientific knowledge (rather than discover the truth). Bloor based the sociology of science on the following principles (here quoted from Finn Collin):

not to discover objective (i.e., mind- or context-independent) truths about the world; that, in any case, there is no way (e.g., a neutral "view from nowhere") for scientists to discover objective truths about the world; that, in any case, there are no objective truths about the world; that, in any case, there is no objective reality-and should recognize the historically-, culturally-, and institutionally-specific nature of their findings." Answer: I did not made these claims, these are something that the reviewer read into the chapter. The pragmatic view of truth and objectivity is complicated, but most pragmatists do think that it is possible to give a pragmatic account of objectivity that avoids bad relativism and conventionalism; see Bernstein (2010, 106-124). 
1. It [the sociology of science] would be causal, that is, concerned with the conditions which bring about belief or states of knowledge. Naturally there will be other types of causes apart from social ones which will cooperate in bringing about belief.

2. It would be impartial with respect to truth and falsity, rationality or irrationality, success or failure. Both sides of these dichotomies require examination.

3. It would be symmetrical in this style of explanation. The same types of cause would explain, say, true and false beliefs.

4. It would be reflexive. In principle its patterns of explanation would have to be applicable to sociology itself. Like the requirement of symmetry this is a response to the need to seek for general explanations. It is an obvious requirement of principle because otherwise sociology would be a standing refutation of its own theories.

These conditions are meant to express a commitment to what Bloor sees as an uncontroversial, mainstream conception of science; thereby, he intends to safeguard the scientific credentials of the programme.

(Collin, 2011, p. 37)

Collin continues pointing out how the above characteristics looks like a commitment, not to scientific rigor as such, but to a commitment to the idealized conception of science constructed and propagated by logical positivism. Other philosophers (e.g., Kjørup, 2008) have also shown how Bloor's ideas are related to those of logical positivism. My own thoughts related to the problem of subject knowledge (or lack thereof) in much of meta-science come to the same conclusion: How is it possible for sociologists to study the activities of scientists without proper knowledge about the subject matter of those activities? (Recall Skinner's interpretation of peoples' reaction to a painting.) How can sociologists decide which acts are important and which are trivial? How is it decided which acts turn out to be fruitful and which are futile? In order to make these decisions, one needs detailed knowledge about the arguments for and against a given theory strengthened or falsified by those acts. To claim that a neutral and objective description of scientific activities is possible without proper subject knowledge is a mistake related to positivist doctrines. As formerly described, such positivist "objectivity" has often been demonstrated as imposing upon the researcher his/her own subjective biases into descriptions and claims.

Social constructivism seems to be based on a paradox: its own research is "true" in claiming the impossibility of objective research. Additionally, it seems to underestimate how difficult it is to produce knowledge and theories that are consistent (i.e., how much resistance reality makes in the construction of theories). While they are right that there is an element of contingency in science this does not mean that scientists can produce any truth they like. We shall return to this issue in relation to bibliometric maps. 
Thomas Kuhn has often been used to support relativists and social constructivists, but Kuhn's philosophy does not imply a strong kind of constructivism (see Wray, 2011) and Kuhn (2000, p. 110) famously rejected the Strong Programme as "deconstruction gone mad". It is important, in the words of Brian Cantwell Smith, "to steer a path between the Scylla of naive realism and the Charybdis of pure constructivism" (Smith, 1996, p. 3). It is ironic that social constructivism -which tend to regard positivism as its enemy par excellence-itself seems to be based on the same problematic assumptions about the neutrality of the researcher. Therefore, (strong) social constructivism is not an alternative to positivism.

\section{Post-Kuhnian perspectives on the meta-sciences}

The issue of "positivism" versus "paradigm theory" is important in all specific sciences (like physics, biology, psychology, and history) as well as in the metasciences described above. In the field of history, Novick (1988) is a valuable example of how the American historical profession has dealt with the idea and ideal of objectivity from its foundation in the 1880s until the book was written. Its particular value is that it describes concretely how the ideal of objectivity was elaborated, challenged, modified, and defended over the last century. The study is based on, among other sources, the archives of the American Historical Review, and is thus a demonstration of how different philosophical norms have influenced decisions for the acceptance of papers for publication in a leading journal (philosophical norms are thus not "merely" philosophical). My analysis of how "postKuhnian" perspectives have changed the meta-sciences does not have the same differentiated and balanced treatment as Novick, but is here presented in a purely schematic and tentative form.

A scientific document is a report by a scientist observing the world and a scientometric study is a report by a scientist observing the reports of other scientists. In both cases, the ways the reports are made reflect norms in the theory of science (even if these norms are implicit or unconscious). The argument is wider, however: Even if the documents are not scholarly papers, they are influenced by philosophical views or ideologies (e.g., by different kinds of -isms in art). All documents are influenced by some views and interests, and all studies of documents are also influenced by some kinds of subjectivity, which are partly culturally and socially shaped. There are thus two levels at play: (1) the traditions and epistemologies underlying document production and (2) the traditions and epistemologies underlying informetrics, information science, and the study of scholarly communication. This paper claims that the important theories of level 1 are identical with 


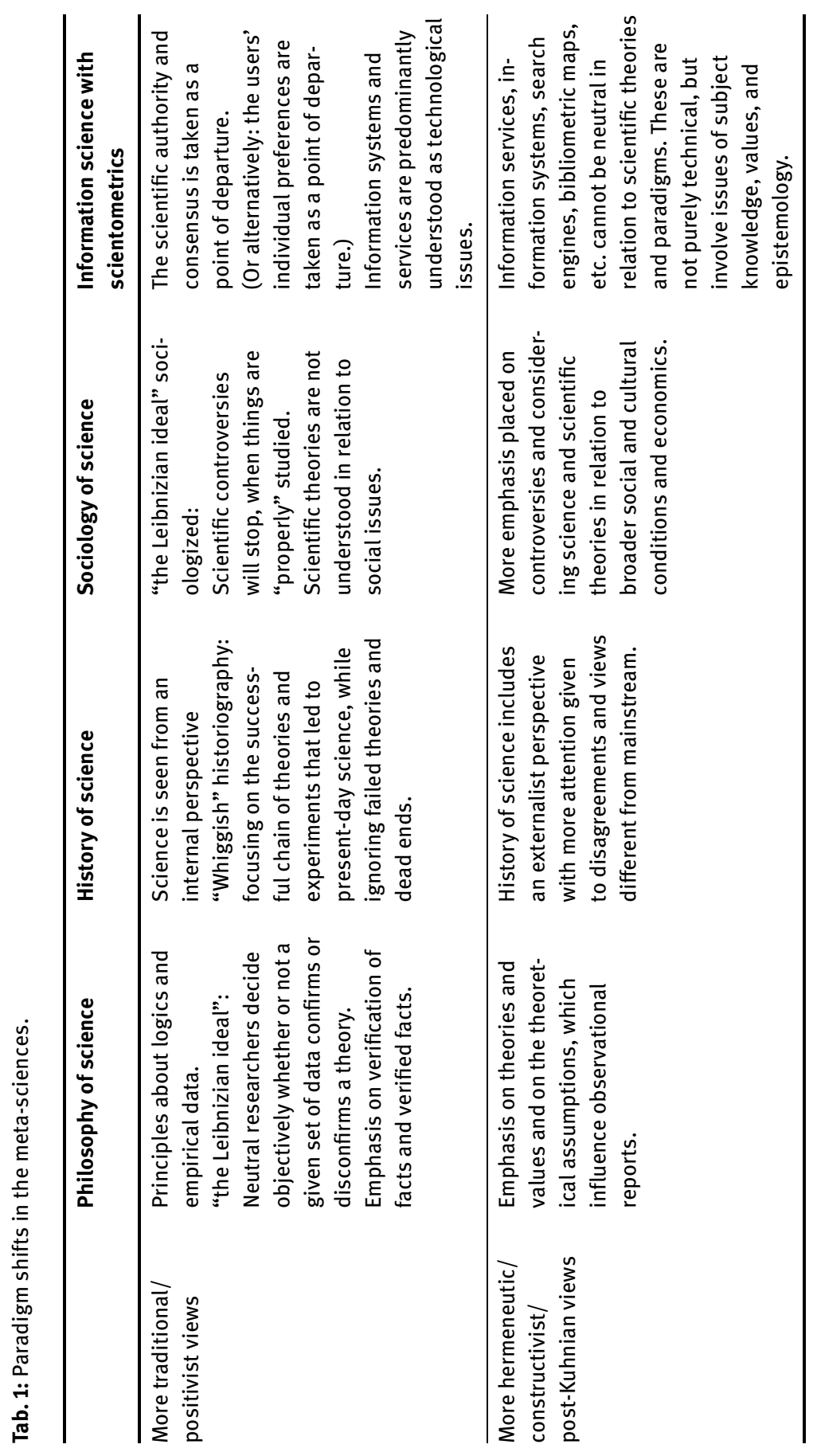


the important theories of level 2 in that both levels may reflect a positivist or alternatively a post-Kuhnian philosophy. How post-Kuhnian perspectives have affected the meta-sciences is outlined in Table 1.

\section{Post-Kuhnian perspectives on informetrics}

Belver C. Griffith (1979) criticised how history and philosophy of science neglected bibliometric findings (including Solla Price, 1965, and his own research). Griffith claims that the empirical studies of science (bibliometrics) have challenged many claims in history and philosophy of science including Kuhn's rejection of "crucial experiments" in physics: "To have taken this image [provided by bibliometrics] seriously would have wiped out many 'hard won distinctions' that philosophers had wrested from their own scholarship" (p. 384). Griffith also praised two books in information science (Brittain, 1970; Meadows, 1974) writing: "The books are, however, philosophically blind-but perhaps nothing really was lost.” In other words, in contrast to this article, Griffith did not expect philosophy of science to be important for information science.

That philosophy is indeed important for science can be expressed with a quote by Albert Einstein:

The reciprocal relationship of epistemology and science is of noteworthy kind. They are dependent upon each other. Epistemology without contact with science becomes an empty scheme. Science without epistemology is-insofar as it is thinkable at all-primitive and muddled.

(Einstein, 1949, p. 683-684) ${ }^{8}$

My aim it thus twofold: (1) To argue about the importance of philosophy of science (against Griffith, 1979, among others, probably including the silent majority of researchers), and (2) to outline what I see as the most important philosophical perspective for informetrics.

\footnotetext{
8 Einstein's relation to positivism is expressed in this quote: "I am not a Positivist. Positivism states that what cannot be observed does not exist. This conception is scientifically indefensible, for it is impossible to make valid affirmations of what people 'can' or 'cannot' observe. One would have to say 'only what we observe exists', which is obviously false” (Einstein, 2005, p. 238). This quote is of course too simplistic to say something about positivism as well as Einstein's philosophy of science-or to indicate that Einstein would support my interpretation of post-Kuhnian philosophy (see Howard, 1993 for a deeper discussion). It is cited only to indicate that positivism is not necessarily the scientists' philosophy and that it is justified to challenge it.
} 


\section{The mirror metaphor}

Griffith's article, entitled Bibliometrics: How faulty a mirror of knowledge? did not, however, address the problem of its title (but was, as mentioned above, a criticism that philosophy of science neglected what he considered relevant bibliometric findings). Here, however, the problem will be directly considered: How faulty a mirror of science is a bibliometric map? (Moreover, how can we examine this?). My first comment concerns the mirror metaphor, ${ }^{9}$ according which scientific knowledge shall be understood as representing a mirror of nature and bibliometric maps as representing mirrors of science.

John Dewey (1929, p. 215) criticized what he labelled "the spectator theory of knowledge" (i.e., the view that the knower is only passively related to the thing known) as did the pragmatic tradition to which he belonged (see also Rorty, 1979). The pragmatic alternative to the mirror metaphor considers knowledge (and knowledge representations such as bibliometric maps) as tools and therefore they do not evaluate them according to how faulty (or how precise) a mirror they provide, but according to how well they fulfil their functions as tools for given tasks (implying that different tasks may require different perspectives). An example: Boyack and Klavans (2010) asked "Which citation approach represents the research front most accurately?" Asking the question this way reveals a view of knowledge corresponding to the mirror metaphor. One of the problems in asking which approach is best is that an answer to that question presupposes that there is a neutral platform from which different approaches may be compared, that we have a key on which to evaluate different approaches. But we do not have such a key; we only have different, more or less equivalent approaches, each of which may claim to be the best. The alternative is to ask: Which bibliometric approach provides the best tool for a given task? Based on this pragmatic view, I consider co-citation analysis and bibliometric coupling as two different approaches that should not be evaluated on providing the most accurate picture, but as different tools suited for different kinds of tasks (see Hjørland, 2013). To understand bibliographical coupling is to understand the degree of overlap in different authors' citation identity, while to understand co-citation patterns is to understand the reception history and scholarly impact of documents. My suggestions may of course be questioned and further examined, but the point here is to follow John Dewey and question the mirror view of knowledge and its use in informetrics today.

9 The mirror metaphor is also known as "the picture theory of knowledge", "the mimetic nature of information", and "the spectator theory of knowledge". 


\section{Selection of sources: a hermeneutical circle}

A strong argument about the non-neutrality of bibliometric maps concerns the selection of the journals (or other sources) on which a given map is constructed. In a former paper I wrote:

Imagine that we are going to create a map of LIS. As Åström (2002) showed, former maps, such as that of White and McCain (1998), seem to have a bias towards information science. In order to provide a better alternative, Åström also included more library-oriented journals in his study. However, there is no objective criterion for judging which documents best represent LIS, and any selected set of journals can always be shown to have a bias in some direction or another.

(Hjørland, 2013, p. 1322; emphasis in original)

Bibliometric researchers are mostly explicit about which journals they used in their studies, and thus about their selection. This means that their research is objective in the sense that other researchers may replicate it. However, the claim put forward here is that bibliometricans do not usually make explicit arguments for how the journals were selected in relation to their conception of the field. It is as if the researchers' view of the domain in question is considered 'obvious' or of no consequence, or that this would provide a kind of subjectivity that is antithetical to the positivist ideals of the authors. White and McCain (1998, p. 329), for example, wrote about co-citation maps: "The maps transcend the viewpoint-and the individual biases-of any one observer." The authors also argued that their choice of journals reflects "mainstream information science" and "journals with strong IS [information science] orientations, as indicated by title and scope statements". However, from my point of view their conception of information science seems to be biased towards "library automation". If I had to make the choice of journals, other journals should have been added (or replaced the library automation journals), because in my conception information science is less technology-oriented and more socially-oriented. My point is that we all have our different views of what the core information science journals are and that such a view necessarily influence study of the field. Therefore a bibliometric map is a subjective representation, not an objective one. Any researcher may have a specific interest (e.g., in facet analysis) and the journals/information sources with the best coverage of that focus could be determined. If not included in the bibliometric investigation, this could be considered a "bias" in the study. This is not an insignificant complaint because such maps are extremely vulnerable to such choices.

A study by Schneider (2010) may also confirm this view:

The highly specialized character of Scientometrics compared to the other journals in this set, i.e., a larger share of publications and the large number of unique authors that only publish 
in the journal, obviously exacerbates the influence of this journal to the arbitrary construct named IS. This raises some important questions on how fields ought to be delimited if at all and how publications should be selected for mapping purposes. It is first of all a sampling problem rather than a normalization problem. It is not a question of right or wrong. It is the simple fact stemming from the phenomena of skewed distributions. Very few mapping studies address this issue.

(Schneider, 2010, p. 257)

Schneider says that the domain under study, information science, is an "arbitrary construct" and that it has important consequences whether a given journal is or is not considered a part of the domain. I see this as a very strong support of my claim that informetrics researchers have to base their studies on an explicate view of what the field is, and what it should be.

We have a kind of hermeneutic circle: How can we identify a field by a set of journals, a set of departments, a set of scholars, etc., unless we already know the field? And how can we know the field unless we know its journals, its research institutions, and its leading scholars? The answer is not that it is hopeless, but that it requires an iterative process whereby the views of the informetrics researchers must be developed, considering the perspective of other meta-sciences, and form their opinion of which views of the field their map is meant to be a tool to support.

A basic principle of critical theory has been formulated in this way:

In retrospect the most important contribution of critical theory to philosophy in the late twentieth century would seem to be their criticism of positivism and their demand that social theory be reflective; that is, that theorists try to be as aware as possible of their own position, the origin of their beliefs and attitudes, and the possible consequences their theorizing might have on what they are studying.

(Geuss, 1998, p. 728)

Using this principle of critical theory in bibliometrics may be termed "critical informetrics" and here we shall have a look at how former bibliometric investigations have been re-examined from such a critical perspective. Spear (2007) criticized former bibliometric studies of the so-called cognitive revolution in psychology. Among his findings are that subfields may develop independently to overall paradigm shifts in a discipline and that scholarly fields may have selfinterest in appearing successful. Therefore, "flagship publications" may not be a good place to look for criticism of main stream assumptions (see also Toomela, 2014, about common assumptions in mainstream research). Spear provided convincing arguments and new empirical results questioning former studies. Spear also emphasised the important ethical issues in simplistic bibliometric conclusions: 
We can argue about indicators, data sources, and forms of analysis, but in the end what we likely learn is that there are many ways to tell a complex story. The problem, of course, is that the outcome of this story has real and important implications for the distribution of organizational resources. If indeed every dean, every granting agency, and every department head "knows" that there has been a cognitive revolution or that a cognitive neuroscience revolution is afoot, then where does that leave the claims of those who do not identify themselves with cognitive psychology or, worse yet, those who identify with behavioral analysis? There is much at stake in how the history of psychology is told.

(Spear, 2007, p. 377)

This may be generalized: there is much at stake in how the history and bibliometric patterns of any domain are represented.

\section{Is the pragmatic/critical view trivial?}

Are informetrics researchers well aware of the importance of the pragmatic/ critical philosophy outlined in this article? Is it a triviality? In my opinion, it is not. Although there have been some critical voices, mainstream research in this field it is still reflecting the positivist model. For example, Henry Small has claimed that co-citation studies-in opposition to manually constructed bibliographies-does not involve subjective decisions:

Either an existing bibliography is used, or subject experts are called upon to comb the literature and select relevant items. The bibliography then becomes the data base for subsequent analyses of the specialty, including its growth and structural characteristics. To the extent that this approach is based upon subjective decisions of relevance by the individual(s) compiling the bibliography, the analysis is open to criticism for possible bias and lack of reproducibility. The principal difficulty with this approach is that it is almost impossible to establish precise criteria as to what should or should not be included within the boundaries of the subject. The method employed here, on the other hand, uses a clustering algorithm to establish these boundaries; it involves no subjective decisions on what is to be included or excluded from the specialty literature.

(Small, 1977, p. 140, italics added)

Precisely the same argument was put forward 37 years later by Andersen, Bazerman and Schneider (2014, p. 317), who wrote: "Scientometric maps provide a kind of description of the cognitive or social structure of a research area independent of subjective judgments and relevance criteria"10 and I have already discussed how Boyack and Klavans (2010) asked "Which citation approach represents the

10 Subsequently Bazerman wrote in an email: "Birger, Good point. [...] Nonetheless, the sentence does not say that the description provided is definitive or an ultimate or fully objective reality- 
research front most accurately" as an example that I find represent mainstream informetrics research. Furthermore, informetric research often uses similarity measures about which Ellis, Furner-Hines and Willett wrote:

Even in the field of numerical taxonomy, where the use of similarity coefficients has been even more widespread than in information retrieval, Jackson, Somers and Harvey (1989) were moved to conclude that 'the choice of a similarity coefficient is largely subjective and often based on tradition or on a posteriori criteria such as the 'interpretability' of the results", and went on to quote Gordon (1987): 'Human ingenuity is quite capable of providing a post hoc justification of dubious classifications.'

(Ellis et al. 1993, 144)

They conclude:

We agree with Kruskal (1964) 'that each scientific area that has use for different measures of proximity should after appropriate argument and trial, settle down on those measures most useful for its needs.' For most applications in information retrieval, the historical attachment to the simple, linear, association coefficients provided by the Dice and cosine formulae is in no need of revision.

(Ellis et al., 1993, 145)

What I miss in this paper-and in the whole of mainstream research in information retrieval and bibliometrics-is the consideration that any two things may be considered similar in many different ways. There is no such thing as measuring similarity objectively. There should always be an argument about the perspective from which two things (e.g., documents) are considered similar. This is a wellknown problem in biological taxonomy in which different species may have developed similar bones and other criteria of similarity in order to adjust to the same environmental possibilities.

There have, of course, been researchers who have pointed out bias, uncertainty, theoretical divergences, and subjectivity in informetrics research (for a compilation, see Cronin \& Sugimoto, 2015). What I believe has seldom-if everbeen claimed explicitly is the principal unavoidability of such bias and subjectivity and, by consequence, the necessity of acknowledgement of the researcher's standpoint.

only that it provides a description that is independent of interpretive judgments. But of course scientometric methods themselves include criteria and procedural judgments. While it is hard to reconstruct my state of mind while revising the text, I likely was thinking that it referred to the kinds of narrative interpretation that historians or participants might give and I did not stop to consider the assumptions embedded within scientometrics. [...] Chuck" 
One argument that my claim is trivial was put forward in an informal communication with a bibliometric scholar:

It is well known that the results of bibliometric investigations often are expressed as probabilities-usually a confidence interval at 95 percent is accepted. In other words is it accepted that there may be up to five percent probability that the result is due to random outcome. This is more or less accepted standard in the social sciences. In this is also given a clear expression that the result is not necessarily "the objective truth".

(Informal communication, January 12, 2015)

This argument does not catch my point, however. One thing is whether there is a statically uncertainty in results, another thing is whether there is a systematic bias due to the researcher's subjectivity. The belief that a certain result is within a certain confidence interval is still based on positivist assumptions. As an anonymous reviewer of this chapter wrote:

The general argument that the results of informetric studies should not be treated as objective truths is by no means new. ${ }^{11} \mathrm{I}$ think there is scope for making reference to a wider selection of previous work, published in the information science literature, in which similar conclusions are drawn.

The reviewer subsequently, on demand, referred to Edge (1979), Hicks (1987), MacRoberts and MacRoberts (1989) and Sullivan, White, and Barboni, (1977).

My first answer is that it is correct that there have been critical voices about bibliometric studies, and I consider the four examples mentioned by the reviewer as being outside mainstream informetrics research. Of these four papers two (Edge, 1979 and Sullivan, White, \& Barboni, 1977) is more in line with my postKuhnian position while the other two seem to be more in line with the positivist position.

Hicks (1987) compared co-citation analysis with a manually generated bibliography in the specialty of "spin glass" and found that co-citation analysis is a "premature" method for science policy decisions, but that further work may improve its reliability and robustness. She describes the subjectivity involved in co-citation analysis but overall her paper seems to suggest-in contradiction to the present chapter-that such subjectivity may be removed when the method becomes mature. She further wrote that "The identification of 'specialties' is fraught with theoretical and empirical difficulties, which remain unresolved" (p. 304), which we have already discussed.

11 See footnote 7 about the pragmatic view of realism and objectivity and the reviewer's misinterpretation of my statements. 
MacRoberts and MacRoberts (1989) discussed seven kinds of problems in citation analysis (i.e., formal influences not cited; biased citing; information influences not cited; self-citing; different types of citation; variations in citation rate placed to type of publication, nationality, time period, and the size and type of specialty; and technical limitations of citation indices and bibliographies). They concluded:

Consequently, whether or not, and in what ways, citations can be used as data remains
unclear and will continue so until all aspects of citation analysis-the theories and assump-
tions that inform it, as well as the data upon which it is based-are subjected to careful
scrutiny. Until this is done, any results obtained by using citations as data will, at best, have
to be considered tentative. (MacRoberts and MacRoberts, 1989, p. 347)

This study also tries to identify kind of errors in order to eliminate them rather than it is reflecting the view that the bibliometric analyst should argue about his or her view of the represented domain (although this view may be implicit in the paper).

Sullivan, White, and Barboni (1977) examined Henry Small's claim that cocitation analysis "involves no subjective decisions on what is to be included or excluded from the specialty literature” and concluded:

The potential biases of which Small speaks [in constructing manual bibliographies] are real, and we find it necessary in our work to be as aware as possible of them. But there are biases involved in co-citation analysis, as well.

(Sullivan, White, \& Barboni, 1977, p. 236)

In other words, this paper confirms the thesis about the subjectivity in informetrics. About the data used for examining the co-citation structure, the authors admit (p. 225): "We do not claim that this intellectual history is necessarily the true picture". The difference between this view and my own view is that I would assume that any intellectual history reflects a specific perspective, and therefore suggests that some work is made illuminating different possible perspectives and how different methodological choices supports one or another perspective.

Edge (1979) is the paper that comes closest to my own view. It discusses quantitative methods in historical and sociological studies of modern astronomy and writes:

... my overall approach is critical. I am not convinced by the stronger claims of the proponents of these quantitative methods. I want to argue that those who adopt these methods (and, in particular, citation analysis) make implicit assumptions about the nature of science: and, moreover, that what they gloss over as unproblematic are precisely the points which many of us find to be crucially at issue.

(Edge, 1979, p. 102) 
One of the important conclusions in his paper is:

These [bibliometric] data certainly make our case more convincing! However, it is important to stress the derivative quality of these figures, which have (in my mind) the status of secondary validation only. Essentially, our picture is derived from our 'soft' data.

(Edge, 1979, p. 126)

Edge is not rejecting quantitative studies, but finds that they should be used critically and based on qualitative knowledge. He is not-as I am-referring to philosophy of science, Thomas Kuhn, critical theory or pragmatism, but his paper is explicitly "critical". Perhaps an explicit engagement with critical philosophy could have made his analyses even deeper by helping to uncover conflicting perspectives and interests in the qualitative and quantitative analysis of the domain.

The examples given in this section demonstrates in my opinion that the philosophical position defended in this paper is not trivial.

\section{The historicist revolution and its implications for informetrics and information science}

We saw that Kuhn introduced a historicist approach in the philosophy of science. The historical perspective has changed biological taxonomy (under the name "cladism") and may also have the potential of making a scientific revolution in information science and informetrics:

Citation analysis can be compared to the paradigm shift in biological taxonomy over recent decades. The classical approach to biological classification (exemplified by the Linnaean taxonomy) is based on classifying organisms on the basis of shared properties (e.g., number of stamens), that is to classify according to similarity of certain properties. Cladism represents a paradigm shift in biology in which organisms are classified solely on the basis of a common ancestor (by Ereshefsky, 2000, called 'the historical approach'). This new approach has made fundamental changes in the classification of plants and animals and this revolution is not yet complete. In the same way as cladism represents a revolution in biological taxonomy, citation analysis may be considered a revolution in KO [knowledge organization] and information retrieval. Both are based on a historical rather than a structural approach to classification. The implication for $\mathrm{KO}$ is that the domains and scholarly traditions to which documents belong are considered their most important criteria of classification (rather than, for example, their statistical word patterns). Scholarly theories determine what is to be considered related and different theories imply different criteria of relatedness.

(Hjørland, 2013, p. 1321) 
Traditional information science and information retrieval tend to consider documents as isolated phenomena and to compare their individual characteristics. ${ }^{12}$ Informetrics is the most obvious perspective to consider documents as part of a tradition and therefore to apply a historicist perspective (although this is not always the case). At this point, it shall just be stated that a more consequent historicist philosophy may have the potential to transform the field in a fruitful direction.

\section{Non-scholarly domains}

We have now considered informetrics in the perspective of the philosophy of science. Are these perspectives also relevant to broader perspectives than just scholarly domains? To make such a generalisation means to move from the theory of science to the theory of knowledge and cognition. My answer is yes: Any domain (e.g., sport, religion, education, law, eHealth or e-commerce) may be perceived differently, there is never just one, neutral and objective, way to describe a field. It is important to consider from which perspective and for which purpose documents are described and the relevance of information is evaluated. Google, for example, is not a neutral search engine (even if we consider only so-called "organic search" as opposed to advertisements). One could say that in principle any search engine is always a cultural-political agent making priorities in relation to what content should be relatively findable and what should remain relatively invisible.

Kuhn's theory has not just been influential in the philosophy of science, but also, for example, in psychology. "Theory theory" (Weiskopf, 2011) is a psychological theory that understands children's thinking as corresponding to scientists' way of thinking: Children have "theories" which may change like paradigm shifts. Therefore, principles from the philosophy of science may have potential as a general foundation for informetrics.

12 An anonymous reviewer commented: "I would disagree, given the emphasis even in 'traditional' information retrieval on measures like tf.idf that take into account the collection-wide frequencies of terms as well as within-document frequencies, on thesauri built on term cooccurrence data, etc. Today's web search algorithms, of course, are heavily link-based, and in no sense treat documents as independent." Answer: Yes, traditional IR often considers documents as parts of collections or as being interlinked. Still, however, they do not consider the single document as part of a genre and a tradition and no of the approaches mentioned by the reviewer can be considered historicist. In biology related methods are known as numeric taxonomic approaches, but they are considered different from cladistics (historical) methods. 


\section{A paradox}

This paper is termed Informetrics needs a foundation in the theory of science. However, the theory of science distinguishes between two kinds of epistemology: (1) Foundationalism (a secure foundation of certainty exists) and (2) Antifoundationalism (no fundamental belief or principle provides the basis or foundation for inquiry and knowledge); justification of knowledge claims is understood here as a function of a relationship between beliefs, none of which are privileged as maintained by foundationalist theories of justification. The paradox is that the philosophical foundation I suggest for informetrics is anti-foundationalism. This is, however, only a contradiction in the word used in the title: there is no contradiction in subscribing to anti-foundationalism.

\section{Conclusion}

The main point raised in the present paper is that insights from the theory of science are important for informetrics. A bibliometric study or measure cannot be judged from a neutral "view from nowhere", but is always-consciously or unconsciously-engaged in the theoretical issues in the field studied. The two most important implications of a post-Kuhnian view of informetrics are:

1. Bibliometric researchers need to consider domain-knowledge and its theoretical foundation: they have to stand in relation to different views on the domain being investigated; and,

2. The objects of bibliometric studies-the documents-must be understood in relation to the broader contexts in which they are produced, used, and cited. Concepts like "research tradition", "paradigms", "genres”, "activity systems", and the like are framework concepts necessary for deeper interpretation and analysis of bibliometric patterns.

Where is Blaise Cronin situated in relation to this view of information science? The following quote illuminates this question:

The texts we write and the texts we cite bear the marks of the epistemic cultures, sociocognitive networks and physical places to which we belong at the different stages of our professional lives.

(Cronin, 2005, p. 1) 
This understanding of "epistemic cultures" and their importance for informetrics and information science reflects the basic idea of the present paper: The fruitfulness of a social and epistemological basis for the field.

\section{Acknowledgment}

Thanks to Cassidy Sugimoto and an anonymous reviewer for fruitful suggestions that improved the article.

\section{Cited References}

Åström, F. (2002). Visualizing library and information science concept spaces through keyword and citation based maps and clusters. In H. Bruce, R. Fidel, P. Ingwersen \& P. Vakkari (Eds.), Emerging frameworks and methods: Proceedings of the fourth international conference on conceptions of library and information science (CoLIS4) (pp. 185-197). Greenwood Village: Libraries Unlimited.

Andersen, J.; Bazerman, C. \& Schneider, J. (2014). Beyond single genres: Pattern mapping in global communication. In: Eva-Maria Jakobs and Daniel Perrin (Eds.), Handbook of Writing and Text Production (pp. 305-322). Berlin: Walter de Gruyter GmbH.

Bates, M. J. (1999). The invisible substrate of information science. Journal of the American Society for Information Science, 50(12), 1043-1050.

Bernstein, R. J. (2010). The pragmatic turn. Cambridge, UK: Polity.

Bird, A. (2004). Kuhn, naturalism, and the positivist legacy. Studies in History and Philosophy of Science, 35(2), 337-356.

Bloor, D. (1991). Knowledge and social imagery. London: Routledge \& Kegan Paul, $2^{\text {nd }}$ edition, Chicago: University of Chicago Press.

Boyack, K. W., \& Klavans, R. (2010). Co-citation analysis, bibliographic coupling, and direct citation: Which citation approach represents the research front most accurately? Journal of the American Society for Information Science and Technology, 61(12), 2389-2404.

Brittain, M. J. (1970). Information and its users: A review with special reference to the social sciences. Bath, UK: Bath University Press.

Chen, C. M. (2003). Visualizing scientific paradigms: An introduction. Journal of the American Society for Information Science and Technology, 54(5), 392-393.

Chomsky, N. (1959). Review of B. F. Skinner's Verbal Behavior. Language, 35(1), 26-58.

Collin, F. (2011). Science studies as naturalized philosophy. Dordrecht: Springer.

Cronin, B. (2005). Warm bodies, cold facts: The embodiment and emplacement of knowledge claims. In P. Ingwersen \& B. Larsen (Eds.), Proceedings of the $10^{\text {th }}$ International Conference on Scientometrics and Informetrics (pp.1-12). Stockholm: Karolinska University Press.

Cronin, B. \& Sugimoto, C. R. (Eds.) (2015). Scholarly metrics under the microscope: From citation analysis to academic auditing. Medford, NJ: Information Today, Inc./ASIST, pp. 976. 
Dewey, J. (1929). The quest for certainty: A study of the relation of knowledge and action. New York: Putnam.

Downes, S. M. (1998). Constructivism. In E. Craig (Ed.), Routledge Encyclopedia of Philosophy (Version 1.0). London: Routledge.

Edge, D. (1979). Quantitative measures of communication in science: A critical review. History of Science, 17(2), 102-134.

Einstein, A. (1949). Remarks concerning the essays brought together in this co-operative volume. In P. A. Schlipp (Ed.), Albert Einstein, philosopher-scientist (pp. 663-688). New York: Tudor Publishers.

Einstein, A. (2005). The quotable Einstein (edited by A. Calaprice). Princeton, NJ: Princeton University Press.

Ellis, D., Furner-Hines, J., \& Willett, P. (1993). Measuring the degree of similarity between objects in text retrieval systems. aPerspective in Information Managementa, 3, 128-149.

Ereshefsky, M. (2000). The poverty of the Linnaean hierarchy: A philosophical study of biological taxonomy. Cambridge: Cambridge University Press.

Feyerabend, P. (1975). Against method. London: New Left Books.

Friedman, M. (2003). Kuhn and logical empiricism. In T. Nickles (ed.), Thomas Kuhn (pp.1944). Cambridge: Cambridge University Press.

Garfield, E. (2004). Historiographic mapping of knowledge domains literature. Journal of Information Science, 30(2), 119-145.

Geuss, R. (1998). Critical theory. In Routledge Encyclopedia of Philosophy, Vol. 2, 722-728. London: Routledge.

Gordon, A. D. (1987). A review of hierarchical classification. Journal of the Royal Statistical Society, Series A (General) 150(2), 119-137.

Griffith, B. C. (1979). Science literature: How faulty a mirror of science? ASLIB Proceedings, 31(8), 381-391.

Hanson, N. R. (1958). Patterns of discovery. Cambridge: Cambridge University Press.

Hicks, D. (1987). Limitations of co-citation analysis as a tool for science policy. Social Studies of Science, 17(2), 295-316.

Hjørland, B. (2013). Citation analysis: A social and dynamic approach to knowledge organization. Information Processing \& Management, 49(6), 1313-1325.

Howard, D. (1993). Was Einstein really a realist? Perspectives on Science, 1(2), 204-251. Retrieved from https://www3.nd.edu/ dhoward1/Was\%20Einstein\%20Really\%20a\%20 Realist.pdf

Jackson, D. A., Somers, K. M. \& Harvey, H. H. (1989). Similarity coefficients: measures of cooccurrence and association or simply measures of occurrence? The American Naturalist 133(3): 436-453.

Kjørup, S. (2008). Menneskevidenskaberne [The human sciences]. $2^{\text {nd }}$ Ed. Vol. 1-2. Frederiksberg: Roskilde Universitetsforlag.

Kleineberg, M. (2014). Integrative levels of knowing: An organizing principle for the epistemological dimension. Advances in Knowledge Organization, 14, 80-87.

Kruskal, J. B. (1964). Multidimensional scaling by optimizing goodness-of-fit to a non-metric hypothesis. Psychometrika, 29(1), 1-27.

Kuhn, T. S. (1962). The structure of scientific revolutions. Chicago: University of Chicago Press.

Kuhn, T. S. (2000). The Road Since Structure: Philosophical Essays, 1970-1993, with an Autobiographical Interview. J. Conant \& J. Haugeland (Eds.). Chicago: University of Chicago Press. 
Lloyd, C. (1993). The Structures of History. Oxford, UK: Blackwell.

MacRoberts, M. H. \& MacRoberts, B. R. (1989). Problems of citation analysis: A critical review. Journal of the American Society for Information Science, 40(5), 342-349.

Mallery, J. C., Hurwitz, R., \& Duffy, G. (1992). Hermeneutics. In S. C. Shapiro (Ed.), Encyclopedia of Artificial Intelligence ( $2^{\text {nd }}$ ed., Vol. 1-2, pp. 596-611). New York: John Wiley \& Sons.

Meadows, A. J. (1974). Communication in science. London: Butterworths.

Moges, A. (2010). Thomas Kuhn: Assassin of logical positivism or its double agent? The Heretic in Philosophy of Science. Retrieved from http://www.galilean-library.org/site/index. $\mathrm{php/page/index.html/ \_ /essays/philosophyofscience/thomas-kuhn-assassin-of-logical-}$ positivism-or-r96

Novick, P. (1988). That noble dream: The "objectivity question" and the American historical profession. Cambridge: Cambridge University Press.

Pedersen, S. A. (1995). Kuhns videnskabsfilosofi, dens udvikling og betydning. [Kuhn's philosophy of science: its development and impact]. In: Videnskabens revolutioner. Ny udgave (pp.7-44). København: Forlaget Fremad.

Price, D. J. de S. (1965). Network of scientific papers. Science, 149(3683), 510-515.

Reisch, G. A. (1991). Did Kuhn kill logical empiricism? Philosophy of Science, 58(2), 264 - 277.

Reisch, G. A. (2005). How the cold war transformed philosophy of science: To the icy scopes of logic. New York: Cambridge University Press.

Rorty, R. (1979). Philosophy and the mirror of nature. Princeton, NJ: Princeton University Press.

Schneider, J. W. (2010). Critical issues in science mapping: Delimiting fields by journals and the influence of their publication activity. Eleventh International Conference on Science and Technology Indicators (pp. 255-257). Leiden, the Netherlands. http://cwts.nl/pdf/ BookofAbstracts2010_version_15072010.pdf\#page $=255$

Small, H. G. (1977). A co-citation model of a scientific specialty: A longitudinal study of collagen research. Social Studies of Science, 7(2), 139-166.

Smith, B. C. (1996). On the origin of objects. Cambridge, MA: The MIT Press.

Smith, L. D. (1986). Behaviorism and logical positivism. A reassessment of the alliance. Stanford University Press, Stanford, CA.

Søndergaard, T. F.; Andersen, J. \& Hjørland, Birger (2003). Documents and the communication of scientific and scholarly information. Revising and updating the UNISIST model. Journal of Documentation. 59(3), 278-320.

Spear, J. H. (2007). Prominent schools or other active specialties? A fresh look at some trends in psychology. Review of General Psychology, 11(4), 363-380. Retrieved from http://www. jmu.edu/socanth/sociology/wm_library/Spear_gpr-11-4-363.pdf

Sullivan, D.; White, D. H. \& Barboni, E. J. (1977). Co-citation analyses of science: An evaluation. Social Studies of Science, 7(2), 223-240.

Toomela, A. (2014). Mainstream psychology. In T. Teo (Ed.), Encyclopedia of critical psychology Vol. 1-4 (Vol. 3, pp.1117-1125). New York: Springer.

Toulmin, S. (1953). An introduction to the philosophy of science. London: Hutchinson.

Tsou, J. Y. (2015). Reconsidering the Carnap-Kuhn connection. In W. J. Devlin \& A. Bokulich (Eds.). Kuhn's structure of scientific revolutions -50 years on (pp. 51-69). Cham: Springer.

Weiskopf, D. A. (2011). The theory-theory of concepts. The Internet Encyclopedia of Philosophy. Retrieved from http://www.iep.utm.edu/th-th-co/ 
White, H. D., \& McCain, K. W. (1998). Visualizing a discipline: An author co-citation analysis of information science, 1972-1995. Journal of the American Society for Information Science, 49(4), 327-355.

Wray, K. B. (2011). Kuhn's evolutionary social epistemology. New York: Cambridge University Press. 